\title{
Effect of density on the compression behaviour of cork
}

Anjos O., Rodrigues C., Morais J., Pereira H., 2014. Materials \&

Design, 53: 1089-1096.

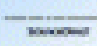

http://www.sciencedirect.com/science/article/pii/S0261306913006663

\begin{abstract}
The compression properties of cork were studied for samples of different density. The densities were grouped into three classes: low density (0.13-0.15), mid density $(0.15-0.19)$ and high density $(0.19-0.25)$. The porosity of the cork samples increased from the low to the high density class, with porosity coefficients of 5.1\%, $6.9 \%$ and $9.4 \%$, respectively. The difference in the porosity was associated with structural features, namely the presence of thick walled cork cells and the presence of lignified cells lining the pores.
\end{abstract}

The stress-strain curves were similar for all cases, showing an elastic compression up to a yield point of about $5 \%$ strain, followed by a plateau with a small slope. The cork strength was higher in the radial direction than in the other directions. The density influenced the compression such that the corks with high density presented higher stiffness in compression in three directions: Young's modulus was 17.4, 22.6 and 26.1 MPa for low, mid and high density corks respectively. This density effect was more evident in the plateau region of the progressive buckling of the cell walls ( $\sigma 30$ was respectively $1.07,1.29$ and $1.54 \mathrm{MPa}$ for the three density classes).

The recovery of dimensions after compression in each direction was also studied following compression to $50 \%$ strain. The recovery was on average $50 \%$ of the initial deformation on the first day, and almost total after 15 days. The recovery was higher for corks with low density and in non-radial directions..

Keywords: cork, density; compression 